\title{
Aquisição da concordância nominal de número: um estudo de caso ${ }^{1}$
}

\author{
The acquisition of number agreement within DP: \\ a case study
}

\section{Leonor Simioni \\ UFSC}

\begin{abstract}
This paper aims at investigating the acquisition of number agreement within DP by a child acquiring Brazilian Portuguese, under the assumptions of the Minimalist Program (Chomsky, 1998; 1999). In the analysis of the child's speech production, I highlight the most frequent patterns of number agreement and plural marking, and discuss three hypotheses (Carstens, 2000; Lopes, 2004; Magalhães, 2004) to find the one which explains the variation within the child's own speech and also between child and adult registers; such hypothesis should also be able to predict how the infant's number agreement patterns will evolve into the adult system. The proposal by Carstens (2000) is the only one which supports the patterns found in the data under analysis, especially the variation between the adult patterns of agreement and plural marking $v s$. the occurrence, in child language, of plural marking morpheme $(-s)$ only on nouns, which is ungrammatical in adult registers.
\end{abstract}

Keywords

Number agreement, Plural marking, Determiner phrase (DP), Language acquisition 


\section{Resumo}

Este artigo visa investigar a aquisição da concordância de número no DP em uma criança adquirindo o Português Brasileiro a partir do quadro do Programa Minimalista (CHOMSKY, 1998; 1999). Ao analisar a fala da criança, destaco os padrões mais freqüentes de concordância de número e marcação de plural, bem como discuto três hipóteses (CARSTENS, 2000; LOPES, 2004; MAGALHÃES, 2004), buscando a que melhor dê conta da variação encontrada na fala da criança e também entre os registros adulto e infantil. Tal hipótese deve também ser capaz de prever como os padrões de concordância de número na fala da criança evoluirão até chegar ao sistema verificado na fala adulta. A proposta de Carstens (2000) é a única que sustenta os padrões encontrados nos dados sob análise, especialmente a variação entre os padrões adultos de concordância e marcação de plural vs. a ocorrência, na fala infantil, do morfema de plural $(-s)$ apenas nos nomes, que é agramatical na fala adulta.

\section{Palavras-chave}

Concordância de número, Marcação de plural, Sintagma determinante (DP), Aquisição de linguagem 


\section{INTRODUÇÃO}

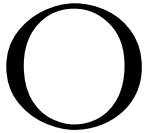

presente trabalho insere-se na perspectiva da Gramática Gerativa, especialmente dos desenvolvimentos recentes do Programa Minimalista (CHOMSKY, 1998; 1999). Tem como objetivos o mapeamento da aquisição da concordância nominal de número $(\mathrm{CN})$ na fala de uma criança adquirindo o Português Brasileiro (PB) em Porto Alegre - RS, evidenciando as estruturas mais recorrentes, bem como a formulação de uma hipótese sintática que dê conta da variação na fala da criança em relação a si mesma e ao adulto. Para tanto, serão analisados os dados de produção espontânea da criança E., de faixa etária entre 1;8 e 3;2 anos de idade. ${ }^{2}$ Para a análise da CN, serão considerados apenas os 91 DPs plurais produzidos no período em questão.

O trabalho está organizado da seguinte forma: na seção 2, esboço a questão da concordância no Programa Minimalista a partir de Chomsky (1995; 1998; 1999), Carstens (2000) e Magalhães (2004) e discuto dois trabalhos sobre a aquisição da CN no PB (FERRARI NETO, 2003 e LOPES, 2004); a seção 3 traz a análise dos dados, na qual podemos perceber uma característica interessante em relação à marcação de plural: a ocorrência de marcação morfológica apenas em N. Na seção 4, discuto algumas hipóteses presentes na literatura que podem explicar os fenômenos atestados nos dados, entre as quais seleciono a proposta de Carstens (2000) por ser a única a efetivamente dar conta dos dados. A seção 5 traz as considerações finais. 


\section{A ESTRUTURA DO DP E A AQUISIÇÃO DA CONCORDÂNCIA: HIPÓTESES MINIMALISTAS}

\subsection{A concordância no Programa Minimalista}

Antes de tratar dos fenômenos de concordância, faz-se necessária uma breve caracterização do que sejam itens lexicais e traços no Programa Minimalista (PM), visto que são elementos essenciais para a presente discussão.

Um item lexical é um feixe de traços, que se subdividem em intrínsecos em oposição a opcionais e interpretáveis em oposição a não-interpretáveis. Os traços intrínsecos estão especificados na entrada lexical, por exemplo, traços formais $(\varphi)$ como gênero gramatical, os chamados plurais anômalos (como o caso do plural do item lexical "óculos") e, nas formulações iniciais do PM, também a informação categorial. Já os opcionais são aqueles cujo valor varia, sendo especificado no momento da seleção para o Lexical Array. No caso do traço de número no $\mathrm{PB}$, portanto, sua presença é um traço intrínseco dos nomes, mas sua especificação como singular ou plural é opcional, sendo determinada a cada nova derivação. Os traços interpretáveis são semânticos e podem, portanto, ser lidos pela interface LF (Forma Lógica), ao passo que os traços $\varphi$ são, em sua maioria, não-interpretáveis. Mais especificamente, a proposta de Chomsky é de que os traços $\varphi$ sejam interpretáveis nas categorias lexicais relevantes (no caso do número, nos nomes).

A proposta inicial de Chomsky para a Teoria de Checagem (1995) determina que esta deve acontecer por meio de movimento de traços (diferentemente da Teoria de Princípios e Parâmetros, na qual havia movimento de categorias), que são atraídos por um alvo (target); mais especificamente, se o movimento dos traços ocorresse antes de Spell-out, a categoria relevante também se movimentaria como free rider. Nesta fase do modelo, o movimento é regido pelo princípio Procrastinate e pela diferença entre traços fortes e fracos: de acordo com Procrastinate, o movimento só se dá na sintaxe aberta, ou seja, antes de Spell-out, quando o traço é forte (não-interpretável em LF), acarretando manifestação morfofonológica.

Em Minimalist inquiries (CHOMSKY, 1998), a idéia é de que não há traços se movendo na sintaxe encoberta, pois a idéia de uma nova "rodada" 
de movimentos após Spell-out recebeu muitas críticas por ser antieconômica e anticíclica; além disso, a partir desse momento, assume-se a possibilidade de mais de um Spell-out por derivação - o chamado modelo de fases. A checagem ocorreria abertamente mediante Agree, entre uma sonda (com traços não-interpretáveis) e um alvo (cujos traços interpretáveis devem combinar com os traços da sonda - o valor não precisa ser o mesmo, apenas o traço). As condições para que Agree aconteça são três: o alvo deve estar no domínio de complemento da sonda; tanto a sonda quanto o alvo devem ser $\varphi$-completos; o alvo deve estar ativo para o sistema, isto é, deve possuir um traço nãointerpretável a ser checado. Já em Chomsky (1999), a interpretabilidade dos traços é determinada pelo léxico, com distinção de valores: traços nãointerpretáveis entram na derivação sem valor especificado, enquanto os traços interpretáveis entram com valores especificados. A relação Agree valora os traços não-interpretáveis da sonda e o Caso do alvo. A proposta de 1999 dá conta ainda da existência de dois mecanismos de concordância: Agree e Concord. Agree seria a concordância descrita anteriormente, no nível da sentença, enquanto Concord funcionaria in situ (isto é, apenas via Merge) apenas no nível do sintagma.

Discuto a seguir duas propostas de análise dos mecanismos de concordância no DP; a primeira diz respeito ao funcionamento de Concord, enquanto a segunda sugere que o mecanismo Agree seja usado para o estabelecimento da concordância também dentro do sintagma, além de propor que, no PB, o traço de número seja interpretável no Determinante. Finalmente, discuto também a proposta de Costa \& Figueiredo Silva (2002), baseada na Morfologia Distribuída, para o tratamento do número no português.

O primeiro trabalho, de Carstens (2000), consiste em uma reformulação de Concord, segundo a qual haveria movimento de N para Num e D; além disso, a autora postula, a exemplo de autores como Ritter (1991) e Delfitto e Schroten (1991), entre outros, uma categoria funcional Num dominando NP, categoria esta que seria responsável pelo número, conforme a representação a seguir (CARSTENS, 2000, p. 328): 


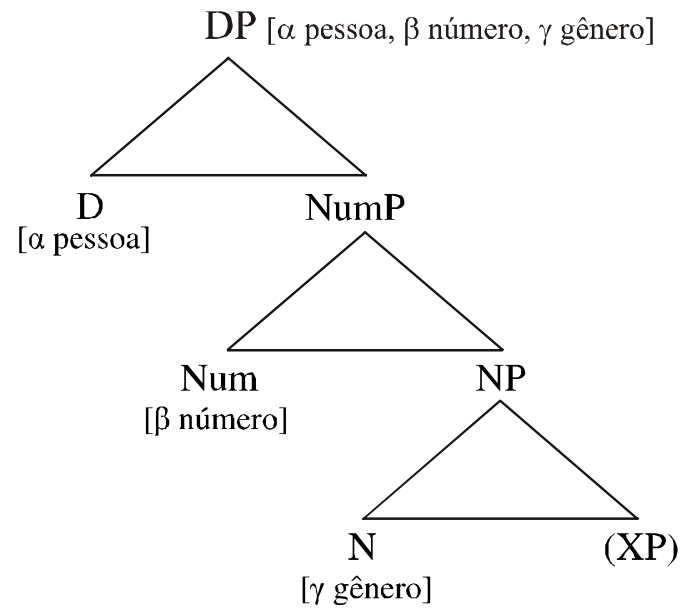

Para Carstens, portanto, D possuiria traços interpretáveis de pessoa e não-interpretáveis de gênero e número; Num possuiria traço interpretável de número e $\mathrm{N}$, traço interpretável de gênero. Assim, o traço não-interpretável de gênero de D motivaria o alçamento de $\mathrm{N}$, que se moveria primeiro até Num e depois até D. Segundo a autora, sob essa perspectiva, "os traços do alvo não têm um status especial na motivação do movimento; se uma categoria possui traços não-interpretáveis, ela pode tanto se alçar quanto 'atrair' um alçamento para fins de checagem"3 (CARSTENS, 2000, p. 324). A vantagem dessa proposta consiste no fato de que a postulação de uma categoria funcional responsável pelos traços de número transferiria esse traço do léxico para a sintaxe, o que poderia, conforme veremos na seção 3 , explicar os estágios iniciais da aquisição da $\mathrm{CN}$ em nosso sujeito sob análise. Se os traços de número estão na sintaxe e não mais no léxico, a proposta de subespecificação das categorias funcionais, presente na literatura gerativista sobre aquisição (proposta, entre outros, por Guilfoyle e Noonan (1988) e Radford (1990)), justificaria em certa medida a marcação de plural apenas em N. Voltaremos a esse ponto na seção 3.

A outra proposta, formulada por Magalhães (2004), vai um pouco mais longe, colocando-se a seguinte questão: como explicar a checagem dos traços do DP utilizando também a operação Agree? A idéia da autora consiste, portanto, em postular um mesmo mecanismo de concordância para os níveis da sentença e do sintagma. Nesse ponto, Magalhães (2004) retoma o trabalho de Carstens (2000), em que, segundo aquela, o mecanismo de concordância 
é baseado em Agree, apresentando movimento e checagem múltipla de traços (N checa iterativamente Num e D). A partir disso, Magalhães (2004), tomando por base também a proposta de Chomsky (1999) para a valoração de traços em construções de particípio, propõe que "a valoração dos traços formais do DP se dá da seguinte maneira: primeiro, os traços ö dos concordantes são valorados entre eles e, em seguida, o DP tem seu Caso valorado por uma sonda" (MAGALHÃES, 2004, p. 156).

Além disso, a autora apresenta uma outra inovação ao discutir em que núcleo do DP o traço de número seria interpretável. Baseada nas análises de Abney (1987), Olsen (1989) e Longobardi (1994), Magalhães (2004) afirma que há evidências de que o traço de número seja interpretável nos Determinantes, diferente do que prevê a hipótese chomskiana. Assim, partindo da estrutura do DP proposta por Abney (1987), a autora teoriza que D tenha traço interpretável de número e não-interpretável de gênero; os demais elementos do sintagma teriam todos os traços não-interpretáveis. Segundo Magalhães (2004), mesmo no inglês, em que o morfema de plural aparece manifesto no nome apenas, há evidências de que o traço seja interpretado em D (o exemplo oferecido é o plural em itens como these, those). É importante salientar que esta autora não assume a projeção Num como o núcleo de uma categoria funcional independente, conforme podemos perceber a partir da estrutura a seguir (MAGALHÃES, 2004, p. 159):

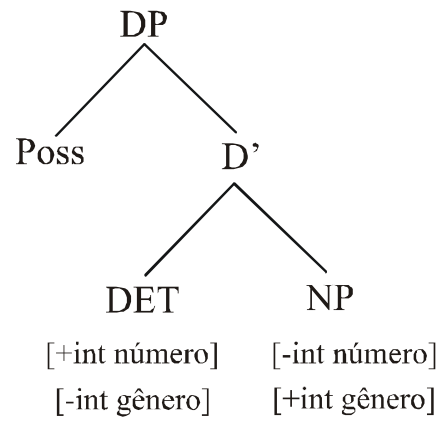


A proposta de Magalhães (2004) busca explicar os fenômenos de concordância no PB respaldando-se em Abney (1987); a autora afirma que, para este autor, há uma relação de s-seleção entre $\mathrm{D}$ e N semelhante à existente em IP entre sujeito e verbo:

No DP, D é o núcleo que seleciona o NP como complemento do mesmo modo que o VP funciona como complemento para Infl. Temos assim uma relação argumento/predicado entre D e $\mathrm{N}$ no sintagma nominal e sujeito e verbo no sintagma verbal. Na sentença, os traços de número são interpretáveis no sujeito (argumento) e nãointerpretáveis no verbo (predicado). O mesmo acontece no DP: traços de número são interpretáveis no $\mathrm{D}$ (argumento de $\mathrm{N}$ ) e nãointerpretáveis em N (predicado). ${ }^{4}$ (Magalhães, 2004, p. 161)

Com isso, tem-se uma explicação para o desaparecimento ou enfraquecimento da flexão nos predicados no PB, gerando estruturas como "Nós vai" ou "As casa velha" em alguns dialetos. Nos dois exemplos, o traço de número só se manifesta no argumento; no momento em que se perde a redundância da realização da flexão nos sintagmas, esta só se realiza no item na qual é interpretável. Com relação à aquisição, poderíamos, de acordo com Ferrari Neto (2003), imaginar que a identificação do núcleo em que o traço é interpretável seja um parâmetro a ser fixado, o que talvez pudesse manter a idéia de que em línguas como o inglês a interpretabilidade do traço estivesse em N. Retomaremos essa análise.

Por fim, o trabalho de Costa e Figueiredo Silva (2002) (doravante C\&FS) apresenta uma proposta de análise da concordância nominal de número no Português Europeu (PE) e em duas variedades do PB, tomando por base o arcabouço da Morfologia Distribuída. ${ }^{5}$ Os autores partem da generalização de que, no PE, a pluralidade é expressa em todas as categorias capazes de portar esse tipo de morfologia (nomes, determinantes, adjetivos, possessivos, quantificadores e demonstrativos). Já os dois registros do $\mathrm{PB}^{6}$ comportamse de forma distinta do PE: a marca de pluralidade aparece somente sobre o determinante, ficando sem marca os nomes e os elementos pós-nominais.

A partir desses dados, a questão levantada consiste na investigação de qual seja a diferença entre a marcação de plural no PE e no PB. A explicação fornecida pelos autores baseia-se na noção de morfema dissociado vs. 
morfema singleton: o morfema de plural no PE seria dissociado, aparecendo em todos os elementos capazes de portar essa marca, enquanto no PB tal morfema é um singleton, manifestando-se apenas no elemento que ancora a informação referente a número; no caso, D, que, segundo Enç (1991), é o núcleo que liga o DP à sua interpretação em LF e pode carregar essa marca em PB.

Antes de confrontar os dados com o que foi exposto até aqui, apresento na seqüência alguns trabalhos sobre a aquisição da concordância de número no PB.

\subsection{A aquisição da concordância de número no Português Brasileiro}

Apresento a seguir dois estudos realizados sob a perspectiva descrita até o momento; minha intenção é, além de dialogar com os resultados de tais pesquisas, evidenciar de que forma os pesquisadores lançam mão das propostas e conceitos minimalistas em suas análises, uma vez que também busco uma explicação teórica adequada para os fenômenos presentes nos dados que pretendo analisar.

O primeiro estudo é o de Ferrari Neto (2003), que trata do reconhecimento do número gramatical e processamento da $\mathrm{CN}$ na fala da criança a partir de duas perspectivas: o bootstrapping fonológico como teoria de processamento lingüístico e o PM como ferramenta de análise lingüística. Os estudos abrangem três experimentos usando o paradigma de seleção de imagens e duas coletas longitudinais com duração de quatro meses, sobre as quais me detenho mais especificamente aqui.

As coletas longitudinais foram realizadas com um menino e uma menina entre os 24 e 28 meses de idade, quinzenalmente; cada sessão durava em média 15 minutos e contava com uma leve elicitação de produção de formas plurais. De acordo com o próprio autor, os dados obtidos não permitem afirmar que crianças nesse período produzam exemplos de concordância no DP, pois não foi registrado nenhum caso. $\mathrm{O}$ que se pode perceber através dos dados é que a criança já é capaz de produzir formas flexionadas em número e que já tem noção do valor semântico do morfema de número. $\mathrm{O}$ autor ressalta ainda que as flexões de número aparecem sempre no nome. Isso significa que há produção e compreensão da noção de numerosidade, mas não necessariamente da concordância. Os experimentos, por sua vez, permitem concluir que as crianças percebem a presença do morfema de número no nome desde muito 
cedo, apesar de não necessariamente processá-la em termos semânticos; além disso, percebeu-se que crianças entre os 18 e 26 meses não demonstram sensibilidade à informação de número presente em $\mathrm{D}$, tampouco à concordância de número entre $\mathrm{D}$ e $\mathrm{N}$. Mais ainda, o maior percentual de respostas corretas obtidas na tarefa de seleção de imagens foi na condição "agramatical", ou seja, com tarefas do tipo "Mostre o gatos pra mim". O autor não oferece uma explicação para o fato; entretanto, ao compararmos esses resultados aos de Lopes (2004) e aos analisados na próxima seção deste trabalho, perceberemos que pode se tratar de uma estratégia inicial da criança, cuja explicação veremos a seguir.

Em relação às hipóteses de interpretabilidade dos traços de número, Ferrari Neto (2003) conclui que

Assumindo-se, como em Chomsky (1995) que o traço de número é interpretável no nome, a identificação do referente com base na informação de número expressa no Determinante é evidência de que a concordância foi estabelecida (no nível da sintaxe aberta). Caso considere-se, como em Magalhães (2002) que o núcleo em que o traço de número é interpretável é um parâmetro a ser fixado, sendo o Determinante o núcleo em que o número seria interpretável no português, então, crianças de 18 meses em diante evidenciam ter levado em conta a informação morfológica que levaria a essa fixação. (FERRARI NETO, 2003, p. 98).

Entretanto, ao analisarmos os dados da coleta longitudinal, percebemos que nenhum deles apresenta concordância entre elementos, sendo a grande maioria de nomes sozinhos. Além disso, muitos desses nomes representam repetições da fala adulta, ou mesmo são fruto de correções por parte do adulto, como no exemplo (1) a seguir:

(1) Assistente: aqui é uma bola, e aqui, duas... bo...

Assistente: aqui tem duas...

A*: bola

Assistente: não, duas bo...

$\mathrm{A}^{*}$....las

(FERRARI NETO, 2003, p. 100) 
Portanto, os dados longitudinais não permitem uma análise acerca da produção de concordância, assim como os experimentos também não permitem concluir se crianças entre os 18 e 26 meses percebem a concordância entre os elementos do DP.

Sobre esse ponto, Corrêa, Name \& Ferrari Neto (2004) afirmam que, no aspecto formal, o valor do traço de número, por ser opcional, é estabelecido quando os itens lexicais são selecionados para compor uma derivação; já do ponto de vista da produção, o valor desse traço é determinado em função da intenção de referência do falante. Na compreensão, por outro lado, o que viabiliza a interpretação semântica do número é a identificação da marcação e de seu valor, somada à identificação de índices do tipo de referência pretendida pelo falante. ${ }^{7}$ Assim,

Uma vez que a interpretação semântica do número gramatical está vinculada ao processamento da referência no DP, é possível que a criança interprete a informação veiculada pelo morfema de número em função da referência, independentemente do modo como a expressão morfológica da concordância de número é veiculada na interface ou mesmo independentemente do modo como a operação de concordância possa se realizar computacionalmente. [...] A interpretabilidade do traço do número gramatical no DP constitui um problema de difícil tratamento semântico [...], não sendo claro de que maneira o traço interpretável de número deverá estar representado no léxico de modo a se fazer presente na chamada interface semântica.

[...] Enquanto gênero é recuperável a partir do nome [...], número constitui uma representação independente deste que pode, em princípio, ser expressa em diferentes posições no DP. [...] A vinculação do número gramatical à referência do $\mathrm{DP}$ e as diferentes formas de expressão do mesmo nesse contexto podem acarretar dificuldades para a criança na identificação do modo como o número se realiza na língua - pelo menos em termos de sua expressão morfológica no DP. [...]

Diante dessas considerações, pode-se prever uma dissociação entre a habilidade de a criança perceber o morfema de número, de interpretá-lo na solução da referência e de distinguir de que modo a concordância de número se expressa no DP. (CORRÊA, NAME \& FERRARI NETO, 2004, p.129-130) 
Já o segundo trabalho é o de Lopes (2004) e refere-se à aquisição de concordância de número no DP, com enfoque especial para o funcionamento dos nomes nus singulares a partir do Parâmetro do Agr Livre, proposta de Schmitt \& Munn (1999) como alternativa ao Parâmetro do Mapeamento Nominal de Chierchia (1998).

A partir de uma breve explanação sobre o funcionamento dos mecanismos de concordância no PB, Lopes (2004) prevê três estágios na aquisição da CN: no primeiro, pressupõe-se um valor singular default e pode haver nomes contáveis singulares nus na fala infantil; no segundo, a criança fixa a diferença de número, sinalizada pela marca morfológica; e, finalmente, no terceiro, a criança fixa a projeção opcional de NumP, de acordo com a proposta de Schmitt \& Munn (1999).

Os dados (duas coletas longitudinais) confirmam a existência do primeiro estágio; entretanto, no que tange ao segundo, as crianças parecem distinguir entre singular e plural, mas o padrão de marcação morfológica (marca de plural apenas do nome) é agramatical na fala adulta. Mais ainda, os dados de Lopes (2004) permitem entrever o que a autora classifica de "tudo-ou-nada": as crianças não apresentam oscilação entre as formas gramaticais e agramaticais; ao contrário, passam de uma fase totalmente agramatical diretamente para a gramática-alvo, seja com marcação morfológica redundante, seja apenas no D.

A explicação fornecida dá conta de que a distinção de número é semanticamente interpretável no nome em um certo ponto do desenvolvimento, enquanto o determinante ofereceria mais dificuldades por envolver operações sintáticas de concordância que levam mais tempo para convergir.

Quanto à interpretabilidade dos traços, Lopes (2004) assume a proposta de Magalhães (2002) em relação à operação de Agree também no âmbito do DP; entretanto, segue a proposta original de Chomsky (1995) segundo a qual o traço de número é interpretável nos nomes. Dessa forma, D é a sonda e No alvo na operação de valoração. Por fim, surge a questão: "o que a criança faz inicialmente, quando número não parece ser valorado em D?" (Lopes, 2004, p. 169). A resposta dada pela autora é a seguinte:

De acordo com nossas assunções, número é um traço interpretável nos nomes, portanto, não tem que ser checado. Assim, inicialmente os traços não-interpretáveis em D ainda não foram selecionados. No 
caso do PB, a criança demoraria mais a convergir em função do traço de número não-especificado nos DPs singulares nus. Isso dá conta do estágio em que a criança marca a morfologia de plural apenas no nome. Naturalmente, os traços não-interpretáveis de D serão considerados adquiridos quando a marcação da morfologia de plural se encontrar em D e não em N. (Lopes, 2004, p. 169)

Conforme veremos na próxima seção, no caso dos dados sob análise neste trabalho, tal hipótese não se sustenta, uma vez que se observa uma forte oscilação entre marcação gramatical e agramatical de plural nos DPs.

\section{O QUE NOS DIZEM OS DADOS? EVIDÊNCIAS EMPÍRICAS}

\subsection{Os dados}

Conforme já mencionado na introdução deste trabalho, serão analisados 91 DPs plurais correspondentes ao período entre 1;8 e 3;2 anos de idade da menina E., observada em coleta longitudinal naturalística entre os anos de 2000 e 2003. Para os dados analisados, as coletas eram realizadas semanalmente e contavam com uma hora de duração.

\subsection{A análise ${ }^{8}$}

Os dados de E. apresentam uma característica bastante interessante em relação à marcação de plural: a marcação morfológica exclusivamente nos nomes. Além dessa marcação, a criança apresenta também dados de produção condizentes com os padrões adultos, quais sejam: a marcação apenas no elemento mais à esquerda do sintagma e a marcação do padrão culto (redundante, em todos os elementos flexionáveis). As tabelas a seguir resumem os percentuais de cada ocorrência: 
TABELA 1

Marcação de concordância padrão nos dados de E.

\begin{tabular}{lccc}
\hline & IDADE & No & \% \\
\hline $\begin{array}{l}\text { Ns } \\
\text { oi vizinhas } \\
\text { depanelinhas }\end{array}$ & $3 ; 0.9$ & & \\
$\begin{array}{l}\text { Formas memorizadas } \\
\text { os sete anões }\end{array}$ & & $7 / 91$ & 7,6 \\
vinte anos & $2 ; 0.2$ & $15 / 91$ & 16,4 \\
$\begin{array}{l}\text { Numeral + Ns } \\
\text { dois dodóis }\end{array}$ & & & \\
$\begin{array}{l}\text { dois pés } \\
\text { Arts + Ns } \\
\text { aspatas } \\
\text { os copos }\end{array}$ & $2 ; 7.17$ & $6 / 91$ & 6,5 \\
Total padrão & $3 ; 0.9$ & & \\
\hline
\end{tabular}

Na primeira tabela, temos os totais de concordância padrão, ou seja, marca morfológica em todos os elementos flexionáveis do sintagma. Chamo a atenção para o alto percentual de formas memorizadas, isto é, aquelas formas que a criança sabe de cor e, portanto, ao menos supostamente não analisa sintaticamente. Nessa categoria, no caso de E., encontram-se principalmente expressões referentes a contos de fadas.

TABELA 2

Marcação não-padrão, esperada nos dados de E.

\begin{tabular}{|c|c|c|c|}
\hline & IDADE & No & $\%$ \\
\hline $\begin{array}{l}\text { Numeral }+\mathbf{N} \\
\text { dois palbaço } \\
\text { dois narizinho }\end{array}$ & $1 ; 10.9$ & $11 / 91$ & 12,0 \\
\hline $\begin{array}{l}\text { Arts }+\mathbf{N} \\
\text { as cadeirinha } \\
\text { os professor }\end{array}$ & $2 ; 8.15$ & 8/91 & 8,7 \\
\hline $\begin{array}{l}\text { Dets }+\mathbf{N} \\
\text { outros trabalbinho } \\
\text { todas folba } \\
\text { tuas mão }\end{array}$ & $2 ; 7.17$ & 3/91 & 3,2 \\
\hline $\begin{array}{l}\text { Sprepo + } \mathbf{N} \\
\text { um monte de bala } \\
\text { Total não-padrão, esperado }\end{array}$ & $\begin{array}{c}2 ; 3.14 \\
-\end{array}$ & $\begin{array}{c}4 / 91 \\
26 / 91\end{array}$ & $\begin{array}{c}4,3 \\
28,5\end{array}$ \\
\hline
\end{tabular}


Na segunda tabela, temos as ocorrências de concordância que não seguem o padrão culto do PB, mas que são amplamente empregados pela população. Observe-se que eles representam, ainda que com pouca diferença, a menor fatia de dados.

TABELA 3

Marcação não-padrão, não-esperada nos dados de E

\begin{tabular}{|c|c|c|c|}
\hline & IDADE & № & $\%$ \\
\hline $\begin{array}{l}\text { Det + Xplural } \\
\text { o dois au-au } \\
\text { esse dois } \\
\text { a duas } \\
\text { o outros } \\
\text { um ólhos } \\
\text { a florzinhas } \\
\text { minha bóias }\end{array}$ & $2 ; 2.26$ & 29/91 & 31,8 \\
\hline $\begin{array}{l}\text { Outros casos } \\
\text { na costa } \\
\text { dua pernas } \\
\text { o teus pezinho } \\
\text { o meus alunos } \\
\text { ólho abertos }\end{array}$ & - & $5 / 91$ & 5,4 \\
\hline $\begin{array}{l}\text { Total não-padrão, } \\
\text { não-esperado }\end{array}$ & - & $34 / 91$ & 37,3 \\
\hline
\end{tabular}

Já a terceira tabela apresenta a marcação considerada agramatical na fala adulta, sobre a qual discorreremos mais adiante. No momento, ressalto apenas a peculiaridade de estruturas como as dos exemplos (2) a (4), nos quais a menina parece: (a) considerar $\mathrm{o}-s$ final do numeral "duas" um morfema de plural, (b) não analisar o $-s$ final de "costas" como um morfema de plural intrínseco, além de marcar a forma "ólho" apenas na abertura da vogal.

(2) dua pernas (E., 2;11.2)

(3) na costa (E., 2;11.2)

(4) ólho abertos (E., 3;0.9)

Através das tabelas, percebemos ainda que o maior índice é justamente o de ocorrências de marcação não-padrão, não-esperada: 37,3\% contra 34\% 
de marcação padrão e 28,5\% de marcação não-padrão, esperada. ${ }^{9,10} \mathrm{O}$ gráfico a seguir nos ajuda a visualizar a distribuição absoluta de cada tipo de dado:

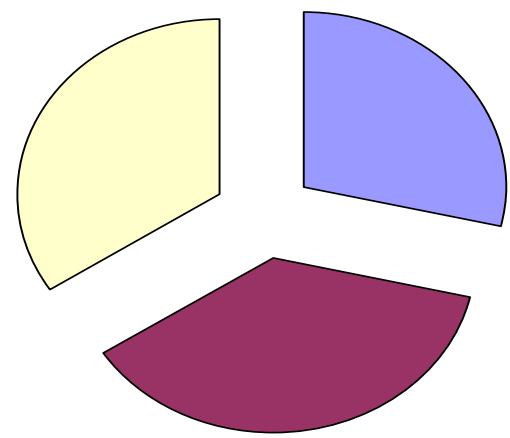

GRÁFICO 1 - Percentagens de distribuição dos padrões de concordância na fala de E

Conforme é possível perceber, a distribuição é aparentemente a mesma nos três casos, com aproximadamente $1 / 3$ de cada tipo de realização de concordância. No entanto, um olhar mais acurado pode nos mostrar que a distribuição talvez não seja tão equilibrada.

A tabela a seguir apresenta uma comparação entre os percentuais dos padrões de concordância e de plural na fala de E.:

TABELA 4

Padrões de plural $v s$, padrões de concordância na fala de E.

\begin{tabular}{lcc}
\hline & № & $\%$ \\
\hline $\begin{array}{l}\text { Formas memorizadas } \\
(2 ; 0.2)\end{array}$ & $15 / 86$ & 17,4 \\
$\begin{array}{l}\text { Dados de plural }{ }^{1} \\
(1 ; 10.2)\end{array}$ & $57 / 86$ & 66,2 \\
$\begin{array}{l}\text { Dados de concordância }^{2} \\
(2 ; 7.17)\end{array}$ & $14 / 86$ & 16,2 \\
\hline
\end{tabular}

${ }^{1}$ Plural apenas no núcleo, ou numerosidade indicada por numerais ou expressões de quantidade.

${ }^{2}$ Apenas aqueles segmentos com marca à esquerda do $\mathrm{N}$ ou com concordância entre elementos flexionáveis. 
Essa tabela indica que, a despeito do que as tabelas iniciais pareciam mostrar, descontando-se dos dados de concordância padrão as formas memorizadas e os sintagmas do tipo Numeral + Ns (que são retirados da análise porque, sintaticamente, nada indica que o numeral esteja efetivamente estabelecendo concordância com o nome), e descontando-se dos dados de concordância não-padrão, esperada os casos de Numeral + N e Sprep0 + $\mathrm{N}^{11}$ (pelo mesmo motivo da exclusão de Numeral + Ns), os percentuais de concordância sintática efetiva são drasticamente diminuídos. É importante destacar que foram descontados da análise os cinco casos colocados na tabela 3 sob o rótulo de "outros casos".

A representação dos percentuais da tabela 4 em forma de gráfico de pizza nos dá uma melhor noção da distribuição dos dados:

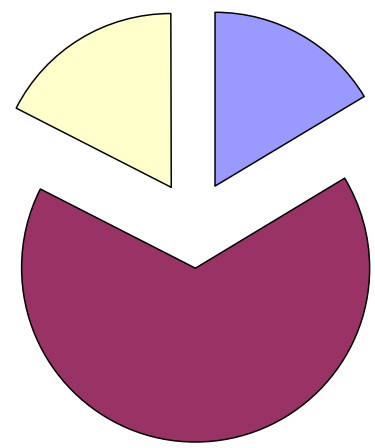

GRÁFICO 2 - Distribuição dos percentuais de concordância e plural nos dados de $\mathrm{E}$

Apesar da representatividade desses dados, não é possível, através deles, selecionar uma das três hipóteses levantadas. Isso porque não se sabe se as ocorrências gramaticais e agramaticais encontram-se em distribuição complementar no tempo (conforme a hipótese de Lopes (2004) e a de Magalhães (2004) a princípio exigiriam) ou se coocorrem. Para isso, apresento os gráficos a seguir, com cruzamentos entre os tipos de dados produzidos por E. e as idades de produção. 


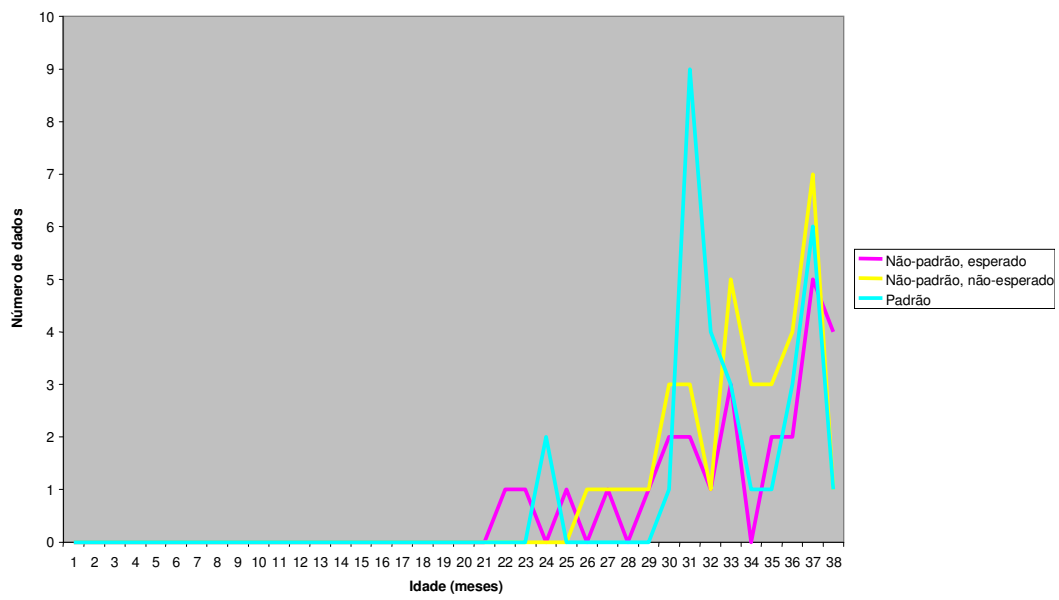

GRÁFICO 3 - Padrões de concordância na fala de E. por idade

O gráfico 3 mostra que, aparentemente, o pico de concordância padrão é maior do que os demais; no entanto, é importante lembrar que estão aí todos os subtipos de concordância padrão, inclusive as formas memorizadas. Além disso, percebe-se que os primeiros dados a surgir são de marcação nãopadrão, esperada, sendo seguidos pela marcação padrão. $O$ último tipo de dados a surgir é, justamente, a marcação não-padrão, não-esperada. $\mathrm{O}$ gráfico a seguir é mais esclarecedor, pois separa os dados de formas memorizadas daqueles de concordância padrão propriamente dita.

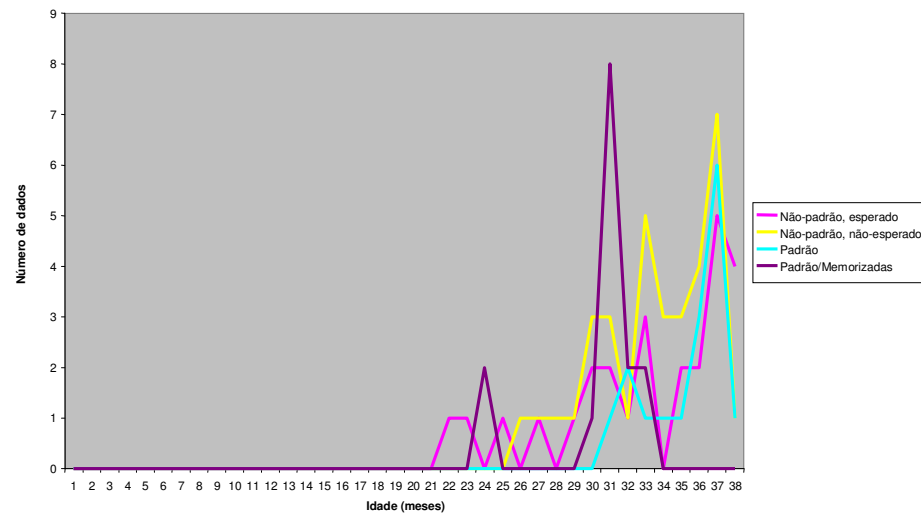

GRÁFICO 4 - Padrões de concordância na fala de E. por idade 
Pelo gráfico 4, percebemos que, na verdade, a emergência dos padrões se dá da seguinte forma: primeiro surge a forma não-padrão, esperada; depois temos ocorrências de formas memorizadas, seguidas pelo surgimento de formas agramaticais e, por último (e não mais em segundo lugar), as formas padrão. Podemos confirmar, também, que o pico de concordância padrão anteriormente observado era, na verdade, constituído por formas memorizadas. Percebemos, igualmente, que os picos das demais ocorrências parecem ser simultâneos, dificultando ainda mais uma possível análise. Apesar disso, após o pico, as formas padrão e não-padrão, não-esperadas decrescem bruscamente, enquanto as formas não-padrão, esperadas mantêm-se no alto. Além disso, temos que as formas padrão surgem bem depois das demais, aos 30 meses $(2 ; 06)$ de idade da menina.

O gráfico 5 apresenta ainda uma subdivisão, baseada nos resultados da tabela 4: marcação padrão com concordância e marcação padrão com plural:

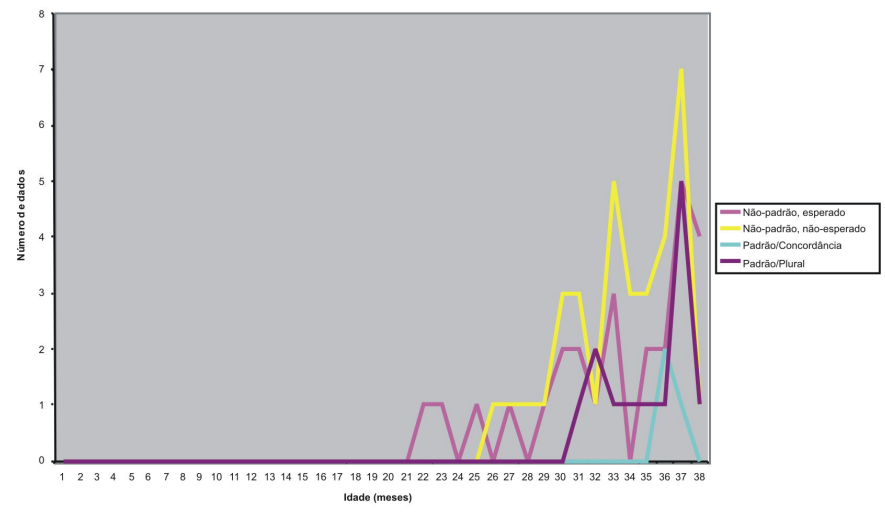

GRÁFICO 5 - Padrões de concordância na fala de E. por idade

A partir desse gráfico, podemos perceber que o maior pico é, agora, o de formas não-padrão, não-esperadas. As formas padrão com plural e nãopadrão, esperadas estão empatadas, mas aquelas decrescem bruscamente, enquanto essas, conforme já visto, se mantêm. Os dados de concordância padrão "verdadeira" encontram-se muito abaixo dos demais, e sua ocorrência inicia-se, na verdade, bem depois das outras, apenas por volta dos 35 meses, ou seja, aos 2;11 anos de idade de E., enquanto as formas não-padrão, esperadas e não-padrão, não-esperadas surgem entre os 21 e os 25 meses (1;09 e 2;01 anos, 
respectivamente). Retomando os dados do gráfico anterior, a marcação padrão iniciada aos 30 meses é, na verdade, aquela que apresenta plural, e não concordância sintática. Ainda assim, esses dados não permitem muitas conclusões, pois a marcação padrão não é a única forma de estabelecimento de concordância no sintagma. Para sabermos quando se consolida o estabelecimento da concordância em E., faz-se necessário um outro tipo de cruzamento.

O gráfico 6 a seguir dá conta da concorrência entre formas plurais e formas de concordância, conforme a tabela 4 .

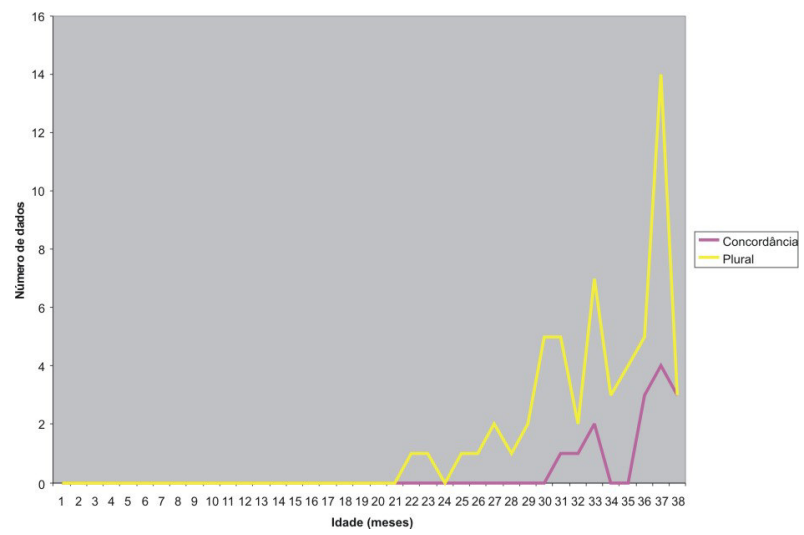

GRÁFICO 6 - Padrões de plural vs. padrões de concordância na fala de E. por idade

O gráfico 6 demonstra que as formas de plural prevalecem fortemente sobre as de concordância. ${ }^{12}$ É importante lembrar que as formas de plural abrangem marcações padrão, não-padrão, esperadas e não-padrão, nãoesperadas; mesmo assim, salta aos olhos a defasagem temporal entre a emergência de um padrão e outro. As formas de concordância (marcação apenas no elemento mais à esquerda do sintagma ou marcação em todos os elementos flexionáveis do sintagma) surgem por volta dos 30 meses, isto é, 2;06 anos de idade, mas só chegam a encontrar as formas de plural aos 38 meses (3;02 anos), no final do intervalo de dados tratado aqui, o que não permite nenhuma conclusão acerca da sedimentação da CN na fala desta criança. Espera-se que, na seqüência temporal dos dados, as formas de concordância superem as de plural, corroborando a fixação dos padrões de concordância; entretanto, tal conclusão somente seria possível a partir de uma análise que contemplasse uma fatia maior dos dados. 


\section{AS HIPÓTESES}

\subsection{Apresentação}

A partir das idéias apontadas na seção 2 e da análise dos dados apresentada em 3, resta-me delinear um modelo de análise que dê conta dos dados analisados. Existem três hipóteses possíveis: (1) traço de número interpretável em N, como nas propostas de Chomsky e no trabalho de Lopes (2004); (2) traço de número interpretável em D, como sugere Magalhães (2004); e (3) traço de número interpretável em Num, conforme a proposta de Carstens (2000). Vejamos agora as consequiências de cada uma delas.

Caso o número seja interpretável nos nomes, o traço será fornecido pelo léxico; ou seja, o item $\mathrm{N}$ entra na derivação já com o valor de seu traço especificado, enquanto D entra com o traço sem valor (conforme a proposta de Chomsky, 1999). Isso explicaria o porquê de a criança, nas fases iniciais, realizar a marca morfológica apenas em $\mathrm{N}$ e não em $\mathrm{D}$. Uma vez que o traço faz parte do léxico, e sabendo-se que itens lexicais como nomes são rapidamente aprendidos pela criança em fase de aquisição, espera-se que haja pouca dificuldade nessa marcação. Além disso, Lopes (2004) afirma que a manifestação de concordância em D seria mais tardia porque esse elemento representa maior dificuldade para a criança em termos de operações sintáticas. Se, como afirma a autora, na fase inicial os traços não-interpretáveis de D não são selecionados, então não há checagem, nem mesmo se pensarmos, nos termos de Chomsky (1995), em sintaxe encoberta (o que em princípio não seria um problema, uma vez que o traço interpretável de $\mathrm{N}$ não precisa ser checado, pois pode ser lido na interface LF). Essa afirmação pode também, no entanto, ser interpretada como uma ausência da categoria funcional DP enquanto tal. Mas o fato é que há realização de material no $\mathrm{D}$, além do que Lopes (2004) afirma claramente não assumir a hipótese de ausência das categorias funcionais defendida por Guilfoyle e Noonan (1988) e Radford (1990). Como, então, haveria a categoria, mas não a possibilidade de checagem (por conta da ausência de traços em D) e, conseqüentemente, de concordância, e mesmo assim haveria derivação? Mais ainda: os dados de Lopes (2004) não apresentam oscilação entre as formas gramaticais e a agramatical, podendo-se, portanto, admitir que D tenha sido adquirido no momento em que a marcação de plural se apresenta manifesta nele. No entanto, 
conforme observado na seção 3, o sujeito pesquisado neste trabalho apresenta tal oscilação; desse modo, a explicação oferecida por Lopes (2004) não daria conta dos dados em questão.

Se admitirmos, por outro lado, que o traço de número é interpretável em D, conforme propõe Magalhães (2004), devemos novamente assumir que o traço já esteja especificado na entrada lexical dos determinantes e, portanto, que esses já entrem na derivação com seu valor especificado. Assim como na hipótese anterior, essa marcação depende de aprendizagem lexical. Entretanto, sabe-se, a partir de diversos estudos (como Guasti et. al., on-line), que, apesar de, como afirmam Ferrari Neto (2003) e Corrêa, Name \& Ferrari Neto (2004), a criança perceber muito cedo a presença dos determinantes, sua aquisição é tardia em relação aos itens lexicais substantivos, pois além de serem itens funcionais, também não possuem stress fonológico. Admite-se, portanto, que a concordância adulta demore a surgir na fala infantil, o que de fato ocorre. Entretanto, a primeira pergunta que surge é: por que inicialmente a criança marcaria morfologicamente o nome, que teria então traço não-interpretável? Pode-se assumir, como Ferrari Neto (2003), que o núcleo em que se dará a interpretação do traço seja um parâmetro a ser adquirido, uma vez que a interpretabilidade em D poderia justificar, conforme já apontado, os atuais fenômenos de concordância em alguns dialetos do PB. Dessa forma, a criança iniciaria admitindo que esse local seja o $\mathrm{N}$ (talvez pelo fato de os itens lexicais serem fonologicamente mais salientes, caso a criança esteja exposta a input de concordância padrão - desmentindo, nesse caso, a hipótese, também de Ferrari Neto (2003), de que a informação crucial à identificação do morfema de número esteja justamente em D). Isso seria em parte justificável em razão da complexidade semântica de $\mathrm{D}$, cuja compreensão envolveria tanto a identificação do valor do traço quanto da referência pretendida pelo falante, conforme apontado na seção 2 por Corrêa, Name \& Ferrari Neto (2004).

Poder-se-ia também assumir a análise de Costa \& Figueiredo Silva (2002), segundo a qual o morfema de número no PB é um singleton. Neste caso, de acordo também com a proposta de Lopes (2004), é possível pensar que a criança produza a marca de plural inicialmente em $\mathrm{N}$ por questões de saliência fonológica. No caso dos dados sob análise no presente trabalho, pode-se supor que a criança realize a marca de plural randomicamente, justamente pelo fato de o morfema ser um singleton. Isso aconteceria porque a criança ainda não teria selecionado os traços relevantes de D, como afirma 
Lopes (2004), ou, como dito no parágrafo anterior, em virtude da complexidade semântica desta categoria, conforme Corrêa, Name \& Ferrari Neto (2004). Qualquer que seja o caso, uma marcação inicial do parâmetro como $\mathrm{N}$ acarretaria necessariamente uma posterior refixação do parâmetro, o que não é uma hipótese preferível, especialmente no caso de haver oscilação entre as duas formas, como parece de fato acontecer, ao menos no caso aqui analisado. ${ }^{13}$ Se não admitirmos que a escolha do núcleo seja um parâmetro, uma explicação plausível torna-se ainda mais complicada: se D possuir desde o início o traço interpretável, e, por conseguinte, $\mathrm{N}$ apresentá-lo não-interpretável, deve haver checagem, pois não parece possível assumir, a exemplo de Lopes (2004) em relação ao D, que os traços não-interpretáveis de $\mathrm{N}$ não sejam selecionados desde o início.

Por fim, se seguirmos Carstens (2000) na idéia de que o traço interpretável de número tem um lugar sintático (a categoria funcional NumP, selecionada como complemento de DP), estaremos admitindo que o traço de número é dado pela sintaxe e não mais pelo léxico, uma vez que não há representação lexical que ocupe Num em português. Dessa forma, temos que o traço de número está disponível desde sempre, por ser uma categoria funcional. A partir disso, levando-se em consideração as teorias gerativistas sobre aquisição da linguagem, podemos supor com o respaldo de autores como Guilfoyle e Noonan (1988) e Radford (1990) que, no momento em que a maturação permite o acesso às estruturas funcionais, licencia-se a concordância (Agree) entre N e Num, configurando-se a passagem da fase 1 de Lopes (2004) marcação singular default - para a fase 2 - marcação apenas em N. Por que não haveria estabelecimento de concordância imediata também entre D e N ${ }^{14}$ É possível imaginar que isso se deva ao fato de a aquisição da categoria D depender de aprendizagem lexical, que também seria possível após um certo nível de maturação, causando uma defasagem, ainda que breve, entre o estabelecimento de concordância entre $\mathrm{N}$ e Num e entre N e D. Poderia ser o caso que, em línguas como o inglês, o processo de aquisição se completasse aí, uma vez que a manifestação morfológica de número nessa língua ocorre apenas em N; não haveria necessidade de avançar mais. ${ }^{15}$ Assim ficaria comprovada a hipótese do léxico como lugar de variação entre as línguas (e, portanto, do que deve ser aprendido). Uma outra possibilidade é de que a categoria $\mathrm{D}$, enquanto categoria funcional, possa estar inicialmente subespecificada. Dessa forma, ainda que a forma fonológica dos determinantes já esteja adquirida, 
talvez haja dificuldades na interpretação da concordância entre os itens do DP, conforme nos apontam os resultados dos experimentos de Ferrari Neto (2003). Além disso, essa proposta está de acordo com a idéia do Parâmetro do Agr Livre, de Schmitt \& Munn (1999), que também postula uma categoria funcional NumP na qual seria fixado tal parâmetro. Segundo Lopes (2004), a fixação desse parâmetro consistiria no estágio 3 da aquisição de concordância, pois sua marcação é opcional para o PB (e depende da aquisição da categoria $\mathrm{D}$, pois diz respeito ao licenciamento de nomes nus). Haveria, portanto, uma seqüência: disponibilização da categoria funcional Num (que não depende de aprendizagem lexical); disponibilização da categoria funcional $\mathrm{D}$ após aprendizagem do léxico relevante; fixação do parâmetro Agr Livre com base no funcionamento conjunto de ambas as categorias.

No entanto, essa hipótese também apresenta alguns problemas: o primeiro deles diz respeito aos casos em que não há oscilação entre formas gramaticais e agramaticais, como parece ser o caso em Lopes (2004); para esses casos, deveríamos supor uma diferença considerável no input. Essa hipótese parece se confirmar, pois, segundo Lopes (2004), seus sujeitos de pesquisa "são filhas de pais altamente escolarizados, expostas, portanto, a um PB bastante padrão" (p. 162). ${ }^{16}$ Outro problema tem relação com a aquisição do gênero, que, segundo o estudo de Name (2002), seria adquirido antes do número; aparentemente, fica difícil sustentar a argumentação feita até aqui, pois, segundo Carstens (2000), N possui traço interpretável de gênero que deve ser checado contra o traço não-interpretável de gênero de D. No entanto, enquanto gênero é um traço intrínseco do nome, que portanto vem com seu valor especificado do léxico, o número tem valor opcional, acarretando processamento extra. A partir disso, poderíamos supor que o processamento da concordância de gênero fosse mais simples. No entanto, não podemos supor que não acarrete algum conhecimento do léxico funcional; menos ainda, que o traço de gênero "pule por cima" de Num e seja checado contra D em uma fase na qual o traço de número ainda não o seja também. A chave para o problema parece, novamente, estar nos dados: a oscilação entre formas gramaticais (marcação padrão ou marcação apenas em D) e agramaticais (marcação apenas em N) de CN começa cedo e dura muito tempo no sujeito sob análise; ou seja, a categoria $\mathrm{D}$ parece demorar a ser sedimentada como tal. Mais ainda, a oscilação parece dar-se, ainda que em menor medida, também em relação ao 
gênero, uma vez que encontramos seqüências como "dois bolinhas" aos 2;8.29 anos de idade da criança (ressaltando que "bolinha" faz parte do léxico conhecido da criança). E é bastante provável que, se estivessem sendo analisados também os DPs singulares, esses casos fossem mais freqüentes. De qualquer forma, considerando apenas os dados sob análise, a concordância de gênero parece consolidar-se não muito antes da $\mathrm{CN}$, o que pode, então, ser explicado pela opcionalidade do traço de número acarretar processamento extra, enquanto o traço de gênero, por ser intrínseco, seria mais facilmente consolidado. Um terceiro problema relacionado é explicar como o sistema evolui, na fala adulta, para uma marcação apenas no determinante; acreditamos que isso se dê em função de D ser o núcleo do sintagma DP e, portanto, o "disseminador" dos traços de concordância, já que Num não apresenta realização lexical em português e, portanto, não poderia ser o "portador fonológico" da marca. ${ }^{17}$

\subsection{Discussão das hipóteses}

A análise dos dados, embora preliminar por não abranger uma faixa maior de dados, permite tirar algumas conclusões em relação às hipóteses discutidas. A mais importante delas diz respeito, justamente, à alternância entre as formas gramaticais e agramaticais até aproximadamente o terceiro ano de vida de E., quando as formas esperadas passam a prevalecer, o que efetivamente excluiria as hipóteses (1) e (2), confirmando minhas previsões. Durante o período de alternância, as formas agramaticais sempre superam as gramaticais em número de ocorrências. Além disso, as formas de concordância emergem tardiamente em relação às formas de plural, gerando o "cronograma" a seguir: emergência das formas de plural não-padrão, esperado (sintagmas com numerais ou PPs indicadores de quantidade) aos 21 meses (1;11 anos); a seguir, emergem as formas de plural não-padrão, não-esperado, aos 25 meses (2;01 anos); um pouco mais tarde, surgem, simultaneamente, as formas de plural padrão e as formas de concordância não-padrão, esperada, aos 30 meses (2;06 anos); por fim, surgem as formas de concordância padrão, aos 35 meses (2;11 anos). Aos 37 meses (3;01 anos), há picos simultâneos de todas as formas, observando-se a seguir uma queda brusca de todas, exceto a concordância não-padrão, esperada, que se mantém.

Dessa forma, creio que a opção (3) seja realmente a melhor explicação 
para os fatos presentes nos dados: as primeiras formas a emergirem, conforme já dito, são formas sobre as quais não podemos ter certeza do estabelecimento de concordância. Logo a seguir, surgem as formas de plural, nas quais já podemos supor o estabelecimento de concordância entre $\mathrm{N}$ e Num. A emergência das formas de concordância não-padrão, esperada pode indicar um início de estabelecimento de concordância entre $\mathrm{Ne} \mathrm{D}$, ainda que de modo assistemático, pois nesse momento emergem também as formas de plural padrão; estes dados podem indicar um "início" de funcionamento da categoria funcional D (a partir de uma aprendizagem mais "sólida" das formas lexicais correspondentes a $\mathrm{D}$, que se proliferam nos dados a partir desse momento), pois, conforme já dito, as formas esperadas e não-esperadas se alternam ao menos até o terceiro ano de vida da criança. Por fim, a emergência de formas de concordância padrão pode ser interpretada como a última etapa do processo de emergência, com concordância plenamente estabelecida entre os elementos do DP. O pico simultâneo de todas as formas aos 37 meses (e especialmente o decréscimo das formas menos tradicionais) pode indicar a consolidação do processo. Um pouco antes do pico, temos, aos 34 meses de E., a coocorrência das formas apresentadas nos exemplos (5) a (7), que parecem demonstrar claramente essa alternância de formas:

(5) dois pés (E., 2;10.19)

(6) um pés (E., 2;10.19)

(7) o pés (E., 2;10.19)

A proliferação das formas lexicais correspondentes a D pode ser confirmada ao olharmos para os dados. Inicialmente, as formas correspondentes a D aparecem predominantemente diante de numeral, como nos exemplos (8) a (10):

(8) a duas mãozinha (E., 2;2.26)

(9) esse dois (E., 2;4.4)

(10) (caiu) o dois (E., 2;6.13)

que não são usos tradicionais. A primeira ocorrência de $\mathrm{D}+\mathrm{N}$ é "as cade(i)rinha", aos 30 meses; de acordo, portanto, com minhas previsões.

Evidências para o início do estabelecimento de concordância entre $\mathrm{N} \mathrm{e}$ 
D podem ser encontradas também nos exemplos (2) a (4), repetidos aqui como (11), (12) e (13), que, apesar de pertencerem às formas agramaticais, apresentam uma característica interessante: uma aparente "análise" dos elementos do sintagma, indicando que a criança, nessa fase, está efetivamente avançando na direção das marcações esperadas, incorrendo inclusive em super-regularização de formas. Note-se que as idades são compatíveis com o cronograma de emergência apresentado anteriormente. Mais ainda, os (poucos) dados que apresentam incongruência na concordância de gênero exemplos (14) e (15) - aparecem nos períodos em que as formas agramaticais prevalecem, o que pode também significar uma evidência positiva para minha hipótese.

(11) dua pernas (E., 2;11.2)

(12) na costa (E., 2;11;2)

(13) olho abertos (E., 3;0.9)

(14) duas brinco (E., 2;7.3)

(15) dois bolinhas (E., 2;8.29)

É preciso ressaltar, no entanto, que a hipótese aqui apresentada não é generalizável, por se tratar de um estudo de caso e por não terem sido considerados dados translingüísticos. De qualquer forma, imagino que a hipótese seja viável também em outras línguas justamente por postular uma projeção responsável pelo número, o que, ao menos a princípio, deve dar uma maior liberdade à ordem de aquisição, corroborando a idéia do léxico como lugar de variação entre as línguas.

\section{CONSIDERAÇÕES FINAIS}

Minha intenção com este trabalho foi analisar os fenômenos de $\mathrm{CN}$ nos dados de E. e, mais especificamente, procurar explicações sintáticas para os tipos de marcações observadas desde a emergência das formas de plural até a consolidação da marcação adulta. Dessa forma, a hipótese de trabalho deveria dar conta da oscilação presente na fala da criança tanto em relação a si mesma quanto em relação à fala adulta, podendo assim prever como se dá a passagem do sistema infantil para o adulto. A proposta de Carstens (2000) pareceu-me a 
única capaz de explicar dos fatos presentes nos dados analisados: em primeiro lugar, a ordem de emergência de padrões de concordância enumerada a seguir, observada nos dados, é sustentada pela hipótese adotada:

(1) emergência das formas de plural não-padrão, esperado (sintagmas com numerais ou PPs indicadores de quantidade), aos 21 meses (1;11 anos);

(2) emergência das formas de plural não-padrão, não-esperado, aos 25 meses (2;01 anos);

(3) emergência simultânea das formas de plural padrão e das formas de concordância não-padrão, esperada, aos 30 meses (2;06 anos);

(4) emergência das formas de concordância padrão, aos 35 meses (2;11 anos).

Além disso, percebi que, mesmo após a emergência da última tipologia de marcação de plural, segue-se ainda um período de alternância, com predomínio das formas não-padrão, não-esperadas. Aos 37 meses, há uma elevação simultânea no emprego de todos os padrões, após a qual há indícios do desaparecimento das formas agramaticais e predomínio das formas nãopadrão, esperadas. No entanto, esta análise é muito preliminar, pois abrange dados de um falante apenas; conclusões mais gerais dependem de estudos mais consistentes em termos de dados.

Restam-me, dessa forma, duas questões principais. A primeira, mais diretamente vinculada a este trabalho, diz respeito à confirmação ou não da tendência apontada anteriormente, que só será possível a partir da análise do restante dos dados de E. A segunda, de caráter mais geral, diz respeito à confirmação da hipótese levantada como a melhor para o tratamento da CN no PB e em outras línguas. Para isso, fazem-se necessários alguns estudos: o primeiro, com dados de mais crianças adquirindo o PB, de preferência provenientes de meios sociais diferentes (em termos da variedade sendo adquirida); o segundo, com dados de crianças adquirindo outras línguas, como por exemplo, o inglês e o italiano. Através de estudos translingüísticos, talvez também fosse possível responder aos questionamentos deixados em aberto na seção 4.1, pois estes também influenciaram na escolha da hipótese de trabalho adotada aqui. $\mathrm{O}$ italiano torna-se extremamente interessante sob esse ponto de vista, pois neste a marcação de gênero e número se dá através de um 
mesmo morfema, o que implicaria aquisição simultânea dos dois sistemas - e, talvez, um problema para minha hipótese preferencial.

\section{NOTAS}

${ }^{1}$ Este artigo é resultado de meu trabalho apresentado como monografia de conclusão do curso de Letras na Universidade Federal do Rio Grande do Sul. Agradeço ao professor Mathias Schaff Filho por sua orientação, bem como às professoras Sabrina Pereira de Abreu e Luciene Juliano Simões pelos valiosos comentários e sugestões.

${ }^{2}$ Fonte: Projeto DELICRI, coord. Profa. Dra. Luciene Juliano Simões, UFRGS.

${ }^{3}$ The features of the target have no special status in the motivating of movement; if a category has uninterpretable features, it may either raise itself or "attract" raising for checking purposes.

${ }^{4}$ Pode-se questionar a comparação estabelecida pela autora entre a relação D-N (núcleo-complemento) e sujeito-verbo (especificador-núcleo). Apesar de tanto $\mathrm{N}$ quanto o sujeito serem argumentos, respectivamente, de D e do verbo, sabe-se que a relação entre núcleo e complemento é mais local e mais forte do que qualquer outra relação estabelecida no interior dos sintagmas (veja-se, por exemplo, o fato de que um complemento jamais viola o Princípio de Extensão).

${ }^{5}$ Os autores tratam da concordância verbal e nominal de número no PE e em duas variedades do PB. Para os fins deste trabalho, discutirei apenas parte da proposta que trata da concordância interna ao DP.

${ }^{6}$ Em relação à concordância interna ao DP, os dados das duas variedades do PB comportam-se da mesma maneira; sendo assim, passarei a unificá-las sob o rótulo de "PB" no que segue.

${ }^{7}$ De acordo com os autores, fazendo-se o contraponto entre a interpretação de número e a de gênero, pode-se dizer que este define a classe denotada pelo nome, enquanto aquele contribui para a expressão da referência.

${ }^{8}$ Parte da análise aqui apresentada foi desenvolvida em conjunto com a Profa. Dra. Luciene Juliano Simões durante meu período como bolsista de iniciação científica no Projeto DELICRI - UFRGS.

${ }^{9} \mathrm{Um}$ dos pareceristas aponta que as diferenças entre os padrões de 
concordância não são significativas, especialmente em vista do baixo número de produções. Concordo com essa afirmação; no entanto, decidi manter aqui as análises estatísticas, não necessariamente elegendo um dos padrões como majoritário, mas apenas como um indicativo concreto dos tipos de produção apresentados pela criança. $O$ ponto mais significativo da presente análise consiste no confronto dos padrões em relação ao eixo temporal, pois este permite entrever um ordenamento na emergência desses padrões que é crucial para a argumentação da seção 4 e a conseqüente escolha do modelo de análise de Carstens (2000).

${ }^{10}$ A marcação não-padrão, não-esperada é a manifestação de marca morfológica de plural apenas em N. A marcação não-padrão, esperada, por sua vez, corresponde à marcação apenas em D ou no elemento mais à esquerda do sintagma, bem como expressões quantificadas com nome no singular (por exemplo, "monte de perna"). Já a marcação padrão diz respeito à manifestação de marcação morfológica de plural em todos os elementos do DP.

${ }^{11}$ Por SPrep0 + N entendemos expressões como "na costa", em que há um sintagma preposicional com nome no singular, sobre os quais não há evidência para o estabelecimento de concordância sintática de número.

${ }^{12}$ As formas de plural são aquelas em que não há evidência morfológica do estabelecimento de concordância entre os itens do sintagma, como aquelas que apresentam marcação apenas em $\mathrm{N}$ ou formas do tipo Numeral + Ns ou Numeral $+\mathrm{N}$, conforme a discussão da tabela 4 . As formas de concordância são aquelas em que há marcação morfológica de plural apenas à esquerda de $\mathrm{N}$ ou aquelas que apresentam concordância morfológica entre os elementos flexionáveis do sintagma.

${ }^{13}$ Apesar das colocações de Corrêa, Name \& Ferrari Neto (2004) sobre a maior complexidade semântica do sistema de número, assumindo-se a proposta de Costa \& Figueiredo Silva (2002), segundo a qual a marca de número se manifesta em D no PB por ser esta categoria a ponte com a interpretação em LF, fica difícil supor que a criança inicialmente não atribua referência aos nomes, muito menos que o faça ora sim, ora não. O problema é semelhante ao encontrado na análise de Lopes (2004).

${ }^{14}$ Vale lembrar que, no modelo proposto por Carstens (2000), Num possui apenas traço interpretável de número e não causaria efeito de interveniência para o estabelecimento da concordância entre D e N. 
${ }^{15}$ Pensando na proposta de Costa \& Figueiredo Silva (2002), poder-se-ia questionar por que em línguas como o inglês a marcação de plural ocorre apenas em N, pois, se o morfema fosse dissociado, deveria manifestar-se em todos os elementos do DP; caso fosse um singleton, deveria aparecer sobre D, visto que esta categoria é responsável pela interpretação em LF. Uma hipótese possível é imaginarmos que o inglês apresente um "morfema zero" de plural nos determinantes. Vale lembrar que, conforme apontado por Magalhães (2004), os demonstrativos em inglês apresentam marcação de plural, ou seja, nos itens em que há possibilidade de manifestação morfológica de plural, esta ocorre; nos demais, teríamos o morfema zero. Essa hipótese, no entanto, carece de maior investigação. ${ }^{16} \mathrm{Um}$ dos pareceristas aponta que, dada a variação de concordância existente no PB, seria estranho supor que as crianças estudadas por Lopes não estejam expostas também à variedade não-padrão. A idéia por trás da afirmação de que a diferença estaria no input é a de que a maior freqüência de determinados tipos de dados em detrimento de outros poderia estar desempenhando um papel na aquisição, o que não descarta a possibilidade, muito provável, de que as crianças em questão estejam expostas também a outros registros. Todavia, tal hipótese necessita de maior investigação, o que está além do escopo deste trabalho.

${ }^{17}$ Além disso, a informação presente na categoria D é crucial para a interpretação em LF. Agradeço à professora Ruth Lopes pelo comentário. Também cfe. Costa \& Figueiredo Silva (2002).

\section{BIBLIOGRAFIA}

ABNEY, S. P. The English noun phrase in its sentential aspect. 1987. Tese (Doutorado) - MIT.

CARSTENS, V. Remarks and replies. Concord in minimalist theory. Linguistic Inquiry, Cambridge, v. 31, n. 2, p.319-355, 2000.

CHIERCHIA, G. Reference to kinds across languages. Natural Language Semantics, 6, p.339-405, 1998.

CHOMSKY, N. The minimalist program. Cambridge, MA: The MIT Press, 1995. . Minimalist inquiries: the framework. MIT Occasional Papers in Linguistics, 15, 1998.

. Derivation by phase. MIT Occasional Papers in Linguistics, 18, 1999. 
FERRARI NETO, J. Reconhecimento do número gramatical e processamento da concordância de número no sintagma determinante na aquisição do Português Brasileiro. 2003. Dissertação (Mestrado) - PUCRJ, Rio de Janeiro.

GUASTI, M. T. et. al. Article omission: across child languages and across special registers. Disponível em: <http://seneca.uab.es/ggt/Gavarro/ galapaperguasti-delange-gavarro.pdf $>$

GUILFOYLE, E.; NOONAN, M. Functional categories and language acquisition. $13^{\text {th }}$ Annual Boston University Conference on Language Development, 1988.

LONGOBARDI, G. Reference and proper names: a theory of movement in syntax and LF. Linguistic Inquiry, v. 25, p. 609-665, 1994.

LOPES, R. E. V. Estágios no processo de aquisição de número no DP do Português Brasileiro. Letras de Hoje, Porto Alegre, v.39, n.3, p.157-171, 2004.

MAGALHÃES, T. M. V. Valorando traços de concordância dentro do DP. Trabalho de qualificação. UNICAMP, 2002.

. A valoração de traços de concordância dentro do DP. DELTA, São Paulo, v.20, n.1, p.149-170, 2004.

NAME, M. C. L. Habilidades perceptuais e lingüísticas no processo de aquisição do sistema de gênero no Português. 2002. Tese (Doutorado) PUCRJ. Rio de Janeiro.

OLSEN, S. AGR(eement) in the German Noun Phrase. In: BHAYY, LÖBEL, SCHMIDT (eds.). Syntactic phrase structure phenomena in noun phrase \& sentences. Amsterdam: John Benjamins, 1989. p.39-49.

SCHMITT, C.; MUNN, A. Bare nouns and the morphosyntax of number. $L S R L$, 29, 1999. 